\title{
The value of subjectivity;
}

\section{Problems and prospects for 360-degree appraisal systems}

\author{
Dr. Beatrice I.J.M. van der Heijden \\ Dr. André H.J. Nijhof
}

Article for:

The International Journal of Human Resource Management

University of Twente

Faculty of Business, Public Administration and Technology

P.O. Box 217 / 7500 AE Enschede /The Netherlands

Phone: ..315348935 19 / Fax: ..31534892159

E-mail: b.i.j.m.vanderheijden@sms.utwente.nl 


\section{Biography}

Dr Beatrice van der Heijden

Beatrice Isabella Johanna Maria van der Heijden (1967) is working as an associate professor at the University of Twente, Faculty of Business, Public Administration and Technology, Department Human Resource Management in the Netherlands. She graduated in work and organisational psychology at the Catholic University of Nijmegen in the Netherlands. Her research activities concentrate on career development and she is leading, respectively coordinating, two European projects, i.e.Indic@tor, 'A cross-cultural study on the measurement and development of employability in small and medium-sized ICT-companies' and NEXT, 'Nurses Early Exit'. Besides, she works as a HRM consultant in both profit and non-profit sector organisations.

\section{Dr ir André Nijhof}

André Nijhof is assistant professor at the faculty of Business, Public Administration and Technology of the University of Twente, Enschede, the Netherlands. His research concentrates on moral responsibilities in processes of organisational change. Stakeholder theory and ethics of care are important theoretical notions in his research. Nijhof has published in several journals like Technovation, Journal of Business Ethics and the Leadership and Organisation Development Journal. Next to the assignment at the University of Twente Nijhof is working at the management consultancy firm Q-Consult in Arnhem. 


\title{
The value of subjectivity
}

\section{Problems and prospects for 360-degree appraisal}

\author{
systems
}

\begin{abstract}
This article focuses on the problems and prospects of 360-degree feedback methods. The rationale behind these appraisal systems is that different evaluation perspectives add objectivity and incremental validity to the assessment of individual performance. This assumption is challenged in this article. Our research shows that there is a consistent difference in especially self- and supervisor ratings. This implies that as long as these differences are understood as the result of several effects in measuring one's performance, the multisource assessments will lead to a false sense of security and objectivity. Instead, when the differences are understood as subjective evaluations with a value in itself, then different perceptions can be used for a better understanding between supervisors and employees of the working relations, personal performance and underlying motives for career development. Several recommendations are made for human resource management practices and future research.
\end{abstract}




\section{Key words}

360-degree feedback methodology, performance appraisals, selfratings versus supervisor ratings, multisource assessments, human resource management, career development

\section{Introduction}

As performance evaluation systems are among the most important and applied human resource components of an organization (Cleveland, Murphy and Williams, 1989; Judge and Ferris, 1993; Smith, Hornsby and Shirmeyer, 1996), it is essential to critically investigate its qualities. In working organizations we have legal and moral pressure to evaluate employees in an objective, consistent and fair way (Bacal, 2000; Greenberg, 1986). In order to comply with this need, specialists create numerical scales. Yet, if we look carefully at the criteria that are used in measurement scales, we will see that they don't eliminate subjectivity at all. One manager's idea of creativity can be quite different from another's idea. Any rating is only an indication of how the person (often the manager) applies a fuzzy criterion. Especially in case of a bad operationalisation of the concept in question, rating systems give people a false sense of security, protection and objectivity.

All assessments, of whatever kind and in whatever context, occur in the cognitive processing of an individual human being. As assessment occurs 'in the head', it is always, necessarily, and by definition, subjective. Now, of itself, this is neither good nor bad, it just is. The important question here is how we respond to the inevitable subjectivity of assessment, and the fact that judgment depends on values and accordingly is subject to response sets, for example due to stereotyping.

For the appraisal of occupational competencies, there is a tendency towards the use of multi-rater or 360-degree appraisals of performance (especially manager performance) (see e.g. 
Cheung, 1999; Yammarino and Atwater, 1997). 360-degree appraisal, also known as multisource assessment or 360 degree feedback, refers to the process by which performance appraisals are collected from different sources of individuals - supervisors, peers, subordinates, and customers, instead of relying on appraisals from a single source (Dunette, 1993; London and Smither, 1995; Tornow, 1993). This should provide the feedback recipient with information not otherwise available, and ensure that raters in the best position to observe certain types of behaviours are the ones to evaluate that behaviour (Ashford and Cummings, 1983). The rationale behind it is that different evaluation perspectives offer unique and valuable information and thus add incremental validity to the assessment of individual performance (Borman, 1998).

For this, it is important to differentiate between the application as a decision making instrument and the application as a developmental tool (see also Waldman, Atwater and Antonioni, 1998). In the latter case the aim is providing constructive feedback in a climate wherein one's growth is fostered and wherein there is room for improving one's weaknesses without immediate negative consequences.

When 360-degree systems are used as a decision making instrument, for example regarding salary or promotion, it has at least the pretension of increasing objectivity. However, Stewart (1998) talks about three problems with regard to this. The first is a philosophical point. Most people feel comfortable with the idea of a continuum between subjectivity and objectivity. Yet, to have a continuum, which by definition is bipolar, both poles must be possible. But if assessment always occurs in the head, and is, therefore, always and inevitably subjective, the objective pole of the continuum is not possible. So, judgments of more or less subjectivity or objectivity are in fact impossible.

Secondly, involving other people in the rating process to ensure fairness and consistency is based on the idea that subjectivity + subjectivity + subjectivity $=$ objectivity! However, if one rater can be unfair and inconsistent, then so can another. 
The third problem arises with the construction and use of criteria. This problem has a number of related issues. First, the extent to which any criteria is understood, in the sense of having the same literal meaning, by all those being assessed and all of those doing the assessing. A genuinely shared understanding of the meaning of concepts is very rare indeed. Second, the extent to which those being assessed have any involvement or contribution to constructing criteria and how they are formulated is very rare too. Third is the fact that the relationship between assessor and assessee is mediated by the specific use of criteria and by the outcomes of the appraisal process (Caligiuri and Lazarova, 2002).

Consequently, a fruitful application of 360-degree appraisal depends upon a careful formulation of criteria, a thorough operationalisations of the concept to be measured and of course a climate wherein people can inform one another on strengths and weaknesses in the performance in particular career stage. The accurate interpretation of differences in appraisal by different sources requires that one can assume each set of ratings uses the same metric. If, for whatever reason, one group of raters interprets the text of an item or a set of items differently than another group, the resulting differences in the ratings may be the result of not only the observations of the raters but also of the interpretative difference elicited by the item (Penny, 2001).

As unequivalent ratings might have various consequences for the employee that is assessed, it is necessary to both examine the extent and the character of the rating differences, and to deal with the question how organizations should cope with discrepancy in ratings in the light of enhancing the individual development of its employees.

This article focuses on the differences between self-ratings and supervisor ratings as a specific part of the broader methodology of 360-degree feedback. Before we elaborate on the outcomes of our empirical work, we will go into the differences between self-ratings and supervisor ratings. Finally, we will discuss the results and the implications for the use of competence appraisals in working organizations following the 360-degree feedback methodology. 


\section{Differences between Self-ratings and Supervisor Ratings for Competence Assessments of Higher Level Employees}

Most studies on organizational behaviour rely on self-reports about the variables of interest. Despite the popularity of retrospective reports, many researchers are rather sceptical about results that come from questionnaires asking people to report about themselves and their performances. They believe that problems associated with informant fallibility strongly influence these reports. Self-ratings appear to be less highly related to ratings by others (i.e., peers, supervisors, or subordinates) than peers', supervisors', and subordinates' ratings with one another (Harris and Schaubroeck, 1988). Self-ratings are also less accurate than ratings from peers or supervisors, when compared to objective criterion measures.

The primary problem is that key informants may not be able to accurately recall the past. As Golden (1992), Huber and Power (1985), Wolfe and Jackson (1987), and many others have suggested, inaccurate recall in retrospective reporting can result from inappropriate rationalizations, oversimplifications, faulty post hoc attributions, and simple lapses of memory. Besides, people are naturally motivated to present themselves in a favourable light, i.e. selfassessment suffers from enhancement or inflation bias (Nisbett and Wilson, 1977).

Some sceptics have noted numerous biases all aimed at protecting self-esteem (Harris and Schaubroeck, 1988; Monson and Snyder, 1977; Nisbett and Ross, 1980; Podsakoff and Organ, 1986; Yammarino and Atwater, 1997). Self-raters are lenient in order to present themselves in 
rosy, socially desirable colours (Cascio, 1991; Cooper, 1981; Golden, 1992; Huber and Power, 1985; Shore and Thornton, 1986; Thornton, 1980; Tsui and Ohlott, 1988). This tendency, called the leniency-effect, is in accordance with the notion that individuals are motivated by drives of self-enhancement, which lead to emphasizing merits and downplaying faults.

In general, self-ratings differ one half to one standard deviation from ratings by supervisors or by near colleagues (Arnold and MacKenzie Daveys, 1992; Harris and Schaubroeck, 1988; Hoffman, Nathan and Holden, 1991; Holzbach, 1978). People are inclined to present themselves in a positive light.

Campbell and Lee (1988) attribute the difference in self-ratings and supervisor ratings to: (1) different perceptions of the job and consequently different assessment criteria; (2) different cognitive processes; and (3) different affective processes (for example, the tendency to present oneself positively, self-denial, and projection).

However, despite doubts on the validity of self-assessment and its utilization in applied research settings, there is reason to believe that individuals are in a good position to make a valid assessment of their own knowledge and capabilities. The person who is doing the job possesses the greatest familiarity with the job and, because of that, is appropriate for filling in the questionnaire. Studies examining job-related variables have shown that those who possess greater familiarity with the job and the ratee (Kozlowski and Kirsch, 1987) provide ratings that are more reliable and have fewer errors (Miller, 1996). Who else has a better understanding of a job and one's functioning in it than the employee him or herself?

Evaluating work performance typically entails assessing multi-characteristic job behaviour. Theories of self-perception (Jones and Nisbett, 1971) have noted that an employee is the one who has access to wide samples of behaviours under varying situations and periods of time. Moreover, every person has unique insight into his or her own inner states, feelings and dispositions, as well as in their changes over time. Levine (1980, p. 261) summarized the advantages of people assessing themselves, saying: "we all have a good deal of time to verify, 
logically and rationally, our feelings about ourselves and our performance, because we have lived with ourselves since we can remember."

In his opinion, self-ratings ought to be appropriate for four reasons. Firstly, people directly experience the effects of their actions in a number of real-world settings. Secondly, they gain information about things in the world around them by observing others. Thirdly, they have also received others' judgements of their performance. Finally, they have had a good deal of time to verify feelings about themselves and their performance. Fox and Dinur (1988) also favour the notion that individuals possess the ability to reliably evaluate themselves in a manner similar to that of others and in a way that can predict subsequent performance.

Accordingly, several reviews of the empirical literature on self-assessments (Mabe and West, 1982; Shrauger and Osberg, 1981; Thornton, 1980) have offered favourable evaluations. When we are aware of the pitfalls that are inherent to the methodology, self-assessment can be of great value when we try to investigate complex phenomena, for example occupational expertise. There are some important possibilities to translate this awareness into measures that can enlarge the validity of the self-assessments.

Mabe and West (1982) have found that the validity of self-assessments is greater in studies where subjects expect their self-appraisal to be validated against external criteria, when the subjects have previous experience with self evaluation, when they are instructed that they should compare themselves with others and when anonymity is guaranteed. They have argued that individuals are influenced by two ongoing motives when they give self-ratings: the desire to present themselves accurately and the desire to present themselves favourably. The availability of social comparison information is integral in increasing the accuracy of self-ratings (Farh and Dobbins, 1989).

In our empirical studies, instructions regarding cross-checking with the ratings of the supervisor as well as anonymity have been used as ways of increasing the validity of the results. As such, we combined the advantages of self-assessments and tried to diminish the unfavourable 
conditions by building in some measures. Like other assessment methods, a method for the measurement of occupational expertise needs to be carefully designed, to use appropriate mixes of different kinds of indicators, and evaluated for its costs and effectiveness.

The resulting research design is quite useful and easy to administer in providing a picture of the degree of occupational expertise. In the next section the methodology of the empirical study will be discussed.

\section{Methodology}

Our empirical research is performed amongst eight large organisations (study one) and 95 small and medium-sized enterprises (study two). In both studies the same questionnaire was used to collect combined ratings from both employees and their supervisors.

\section{Samples and Data Collection Study One Executed in the Year 1995}

In each organisation involved in this study, once the agreement was made to participate, a discussion with a representative from the personnel department followed. There was an explanation of the criteria for participation and we made samples of employees appropriate for our questionnaires. These criteria concerned the minimum level of functioning of the employees (middle or higher level employees), with the target of an equal distribution over three age groups (20-34 years, 35-49 years and 50+) and a reflection of different types of existing functions in the organisation.

Until twenty years ago, simple functions and simple tasks were dominant in most working organisations. As a consequence, the bulk of older employees in our existing working population has a rather low level of education. As the complexity and level of difficulty of future functions will on average be higher than it is now, we have every reason to expect that the average educational level will likewise have undergone a sharp rise by the year 2010. In Table I, the number of respondents for each organisation is given. A subdivision is made for the two different data sources: the employees and their corresponding immediate supervisors. 
Table I. Number of response rate of employees and supervisors, per organisation

\begin{tabular}{|c|c|c|}
\hline Organisation & Number and & Number and \\
\hline & $\begin{array}{l}\text { response rate of } \\
\text { self-ratings }\end{array}$ & $\begin{array}{l}\text { response rate of } \\
\text { supervisor ratings }\end{array}$ \\
\hline Akzo Nobel & $93(30.5 \%)$ & $94(39.7 \%)$ \\
\hline Hewlett Packard & $42(65.6 \%)$ & $48(75.0 \%)$ \\
\hline Ministry of Justice & $53(31.4 \%)$ & $41(24.3 \%)$ \\
\hline Ministry of Transport, Public Works and Water & $64(37.2 \%)$ & $82(47.7 \%)$ \\
\hline \multicolumn{3}{|l|}{ Management } \\
\hline Philips Communications and Processing Services & $81(25.4 \%)$ & $60(18.8 \%)$ \\
\hline \multicolumn{3}{|l|}{ Rabobank Organisation } \\
\hline Unilever Research Laboratory & $72(75.0 \%)$ & $79(82.0 \%)$ \\
\hline \multirow[t]{4}{*}{ University of Twente } & $135(35.0 \%)$ & $33(25.6 \%)$ \\
\hline & $19(100.0 \%)$ & $17(89.5 \%)$ \\
\hline & Total: & Total: \\
\hline & $559(50.0 \%)$ & $454(50.3 \%)$ \\
\hline
\end{tabular}

Despite the effort to obtain a balanced division of the two sexes in this study, from the total sample $83.4 \%$ of the respondents is male and $16.6 \%$ is female. However, it is generally known that in the higher regions of the organisation most functions are fulfilled by men. In this respect, the composition of our sample can be interpreted as an advantage because the division is in fact really representative for the actual situation in Dutch working organisations and consequently more accurate. The age distribution in the final sample of individual employees is as follows: starters (20-34 years) 27.4\%, middle-aged (35-49 years) 45.8\% and seniors (50+) 26.8\%.

\section{The Survey}


In the survey, two types of questionnaires have been used to determine the relationship between job-related predictors and occupational expertise. Questionnaire A pertains to the self-ratings of occupational expertise and had to be filled in by the individual employee while item set $\mathrm{B}$ had to be filled in by the corresponding immediate supervisor. Item-sets $\mathrm{A}$ and $\mathrm{B}$ are nominally identical, except for the fact that the items in the self-ratings questionnaire refer to the employee him or herself, and the ones in the questionnaires for the supervisors refer to a particular employee.

For the measurement of occupational expertise a questionnaire was used consisting of 78 items in total (Van der Heijden, 1998). All items refer to attributes or behaviours typically attributed to experts or outstanding performers in various field. Each item referred to one of the five dimensions.

In administering the questionnaire to the supervisors, all items were adjusted into sentences like: "In that period my employee fulfilled the role of mentor for ..." and "I think that my employee is ... at adjusting flexibly to technological changes". A six-point rating scale was added to each item rating from 1 ("very little", "never", "not at all”, "very small”, "very uncertain" and so on) to 6 ("very great deal of", "very often", "extremely", "to a considerable degree", "very large", "highly unsuitable", "very good" and so on - wording dependent on item content) on which an individual's assumed position, relative to the item in question, could be measured.

For a full appendix of the questionnaire (the original Dutch version and its English translation), and a thorough outline on the operationalisation of the concept of occupational expertise in five measurement scales and the psychometric evaluation from both a pilot study as well as the main study, see Van der Heijden, 1998 and 2000. In table II the reliability coefficients, using Cronbach's $\alpha$ are given.

Table II. Reliability coefficients of each scale as expressed by Cronbach's $\alpha$ 


\begin{tabular}{lccc}
\hline \multicolumn{1}{c}{ Scale } & Number of items & Alpha self-ratings & Alpha supervisor ratings \\
\hline Knowledge & 17 & .83 & .93 \\
Meta-cognition & 15 & .86 & .94 \\
Skill requirement & 12 & .84 & .94 \\
Social recognition & 15 & .83 & .94 \\
Growth and flexibility & 19 & .87 & .93 \\
\hline
\end{tabular}

For each scale of occupational expertise, the reliability of the supervisor ratings is higher compared with that of the self-ratings. It has been suggested (Van der Heijden, 1998) that the greater directional diversity (lower inter-item coefficients) of the self-ratings does not prove that employees give a less valid, but rather a somewhat more differentiated self-image. Each item refers to different behaviour, a different behavioural style or a different outcome. Moreover, we have to bear in mind the fact that supervisors, although responsible, tend to be only superficially acquainted with their employees, especially as far as the higher level employees are concerned.

Samples and Data Collection Study Two Executed in the Year 2000

Study one has been replicated in small and medium-sized enterprises (SMEs). Two different entrances have been used in order to obtain a substantial sample. Both the AWVN (General Employers' Association in the Netherlands) and Atrivé (A Dutch Consultancy Organization for Social Housing Associations, Governments, Housing and Healthcare Combinations) have announced the study in a newsletter for the organizational members. There was an explanation of the criteria for participation and we made samples of employees appropriate for our 
questionnaires. These criteria concerned the maximum size of the company, i.e. 150 employees, the minimum level of functioning of the employees (middle or higher level employees), with the target of an equal distribution over three age groups (20-34 years, 35-49 years and 50+) and a reflection of different types of existing functions in the organization (see the previous section for further details concerning the sampling).

Initially, 147 organizations have agreed to participate with, aggregated, 435 pairs of employees and their direct supervisors. In the end, data have been gathered in 95 organizations, including 233 employees and 217 direct supervisors, i.e. 194 pairs. These outcomes imply a response rate of $53.6 \%$ for the employees and $49.9 \%$ for the direct supervisors. In Table III, the number of respondents for each branch is given. A subdivision is made for the two different data sources: the employees and the supervisors.

Table III. Number of employees, supervisors and combined ratings, per branch

\begin{tabular}{|c|c|c|c|}
\hline Branch & $\begin{array}{l}\text { Number of self- } \\
\text { ratings }\end{array}$ & $\begin{array}{l}\text { Number of } \\
\text { supervisor ratings }\end{array}$ & $\begin{array}{l}\text { Number of } \\
\text { combined ratings }\end{array}$ \\
\hline Agriculture including fishing industry & $8(3.4 \%)$ & $8(3.7 \%)$ & $8(4.1 \%)$ \\
\hline Manufacturing industry & $29(12.4 \%)$ & $24(11.1 \%)$ & $19(9.8 \%)$ \\
\hline Building industry and installation & $4(1.7 \%)$ & $5(2.3 \%)$ & $3(1.5 \%)$ \\
\hline Retail and leisure (including restaurants) & $9(3.9 \%)$ & $8(3.7 \%)$ & $6(3.1 \%)$ \\
\hline Transport and communication & $5(2.1 \%)$ & $3(1.4 \%)$ & $3(1.5 \%)$ \\
\hline $\begin{array}{l}\text { Business services (banks, consultancy and } \\
\text { insurances) }\end{array}$ & $26(11.2 \%)$ & $25(11.5 \%)$ & $24(12.4 \%)$ \\
\hline $\begin{array}{l}\text { Public services (civil services, education and } \\
\text { healthcare) }\end{array}$ & $143(61.4 \%)$ & $144(66.4 \%)$ & $131(67.5 \%)$ \\
\hline Unknown & $9(3.9 \%)$ & $0(0 \%)$ & \\
\hline & Total: & $\begin{array}{l}\text { Total: } \\
217(100 \%)\end{array}$ & $\begin{array}{l}\text { Total: } \\
194 \text { pairs }(100 \%)\end{array}$ \\
\hline
\end{tabular}


Despite the effort to obtain a balanced division of the two sexes in this study, from the total sample $68.0 \%$ of the respondents is male and $32.0 \%$ is female. However, it is generally known that in the higher regions of the organization men fulfil most functions. In this respect, the composition of our sample can be interpreted as an advantage because the division is in fact really representative for the actual situation in Dutch SMEs and consequently more accurate.

The age distribution in the final sample of individual employees is as follows: starters $31.3 \%$, middle-aged $45.5 \%$ and seniors $23.2 \%$. In table IV the reliability coefficients, using Cronbach's $\alpha$ are given.

Table IV. Reliability coefficients of each scale as expressed by Cronbach's $\alpha$

\begin{tabular}{lccc}
\hline \multicolumn{1}{c}{ Scale } & Number of items & Alpha self-ratings & \multicolumn{2}{c}{ Alpha supervisor ratings } \\
\hline Knowledge & 17 & .84 & .90 \\
Meta-cognition & 15 & .88 & .91 \\
Skill requirement & 12 & .83 & .88 \\
Social recognition & 15 & .84 & .89 \\
Growth and flexibility & 19 & .85 & .92 \\
\end{tabular}

Again, for each scale of occupational expertise, the reliability of the supervisor ratings is higher compared with that of the self-ratings (see also Van der Heijden and Verhelst, 2002). The results for study one and two are very similar implying that our interpretation of the results is supported by two empirical sets of data obtained in different research settings. 


\section{The Outcomes of the empirical studies}

Since quite a number of combined ratings have been collected from both employees and from their immediate supervisors, namely 313 for study One, and 194 for study Two, interesting comparisons between the two sources of raters could be made.

It should be remembered that the employees rated in our study work in the higher ranks of their organizations. At these levels, employees and supervisors respect their own separate responsibilities and often only intermittently see and speak to each other. Besides, it is known from the study 'Over-forties in the organisation' (Boerlijst, 1994; Boerlijst and Van der Heijden, 1996; Boerlijst, Van der Heijden and Van Assen, 1993) that the period during which supervisors and employees know and have to do with each other tends to be relatively short. As a result, there is a lack of interest in the further development of the employee on the part of the management. A considerable gap is therefore to be expected between both parties' points of view.

By combining the advantages of self-assessments and diminishing the unfavourable effects from possible pitfalls of these, we have tried to maximize the quality of our study results. We expect our self-ratings to be less susceptible to the commonly found leniency effect, owing to the instruction regarding cross-checking with the supervisor ratings. Each respondent received an envelope with a questionnaire and an accompanying letter with details on the procedure, including the remark that the supervisor was to give his or her judgement as well.

Furthermore, anonymity has been guaranteed, implying that the need to present oneself favourably has been diminished. The ratings have been performed in a confidential atmosphere, reassuring the ratees that no personal information would be transferred to any official agency in the organisation. It is therefore assumed that our ratings are less strongly biased.

In Table V and VI, the outcomes of the paired samples comparisons are given. First, the descriptive statistics of the pairs are presented. Next, the results of the paired samples T-tests and paired samples correlations are given. 
Table V. Paired samples T-tests and paired samples correlations, study One

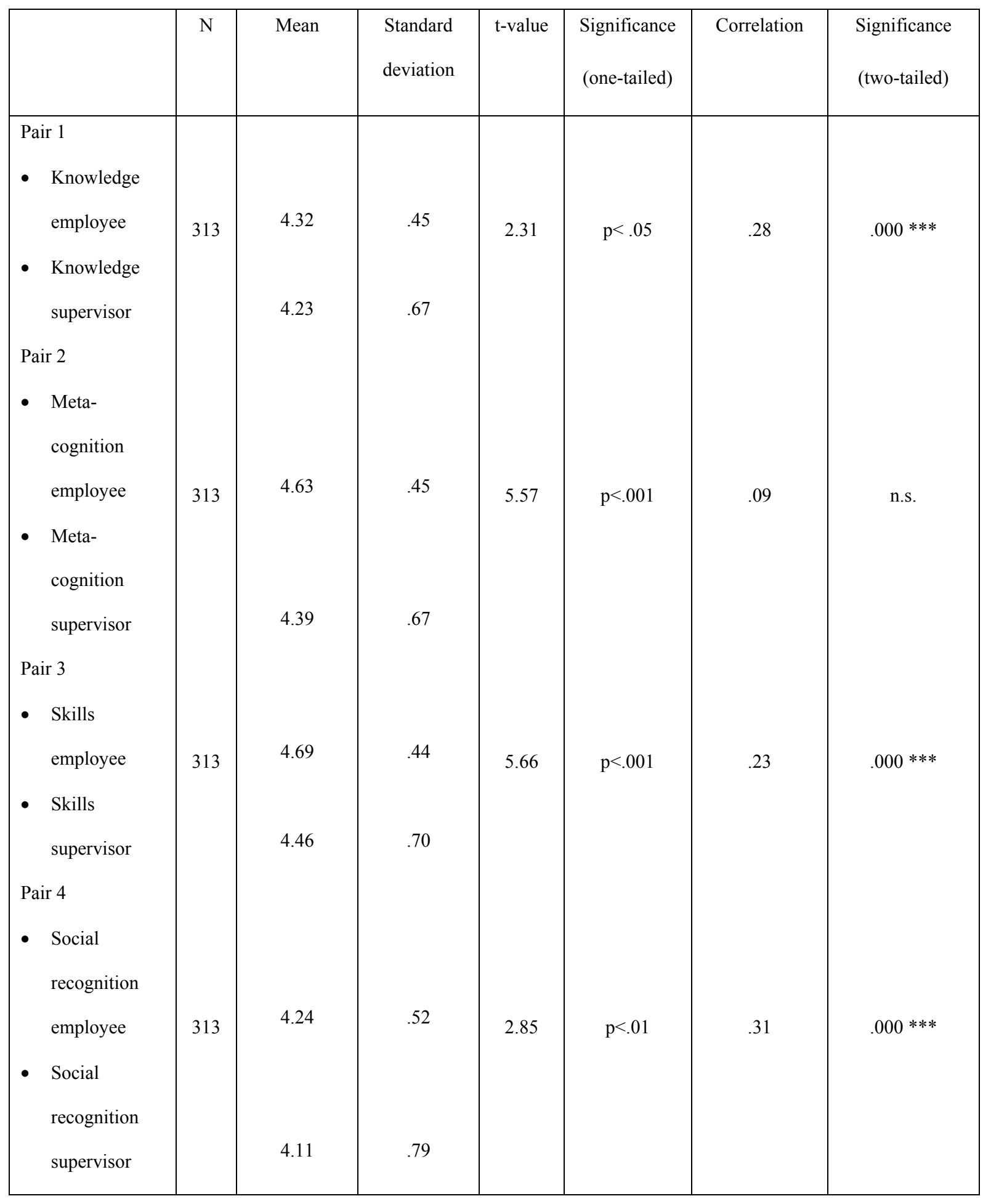




\begin{tabular}{|l|l|l|l|l|l|l|l|}
\hline $\begin{array}{l}\text { Pair 5 } \\
\text { Growth and } \\
\text { flexibility } \\
\text { employee }\end{array}$ & 313 & 4.08 & .51 & 7.08 & $\mathrm{p}<.001$ & .27 & $.000 * * *$ \\
- $\begin{array}{l}\text { Growth and } \\
\text { flexibility } \\
\text { supervisor }\end{array}$ & & 3.81 & .67 & & & & \\
\hline
\end{tabular}

(N.s. not significant, $* \mathrm{p}<.05, * * \mathrm{p}<.01, * * * \mathrm{p}<.001)$

Table VI. Paired samples T-tests and paired samples correlations, study Two

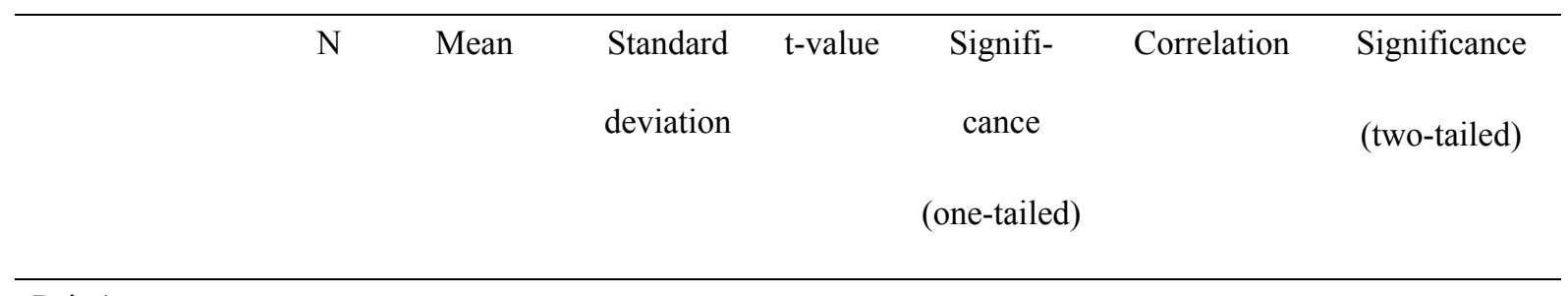

Pair 1

- Knowledge

employee

$194 \quad 4.26$

.43

$-1.91$

n.s.

.30

$.000 * * *$

- Knowledge

supervisor

$4.18 \quad .56$

Pair 2

- Meta-

cognition

employee

$194 \quad 4.63$

.44

$-5.60 \quad \mathrm{p}<.001$

.15

$.038^{*}$

- Meta-

cognition

4.36

.56

supervisor

Pair 3 
- Skills

employe

$194 \quad 4.70$

.40

$-4.15 \quad \mathrm{p}<.001$

.18

$.015^{*}$

- Skills

supervisor

4.52

.51

Pair 4

- Social

recognition

employee

$194 \quad 4.16$

.49

.47

n.s.

.34

$.000 * * *$

- Social

recognition

supervisor

Pair 5

- Growth and

flexibility

3.98

.46

employee

194

- Growth and

$\mathrm{p}<.001$

.27

$.000 * * *$

flexibility

supervisor

(N.s. not significant, $\left.{ }^{*} \mathrm{p}<.05, * * \mathrm{p}<.01, * * * \mathrm{p}<.001\right)$

All inter-method correlations except one are positive. 'Convergence' of two indicators of one and the same expertise scale supports the validity of both. If the two scores (from the two sources of raters) truly measure the same construct, without impurities, they give the same answer in any comparison of individual employees (to the extent reliabilities permit) (Cronbach, 1990).

The exception concerns the corresponding ratings on the meta-cognitive knowledge scales in study one, which correlate .09 . The rest lies between $r=.23$ and .31 (both N's $=313$ ) for study 
One, and between .15 and .30 (both N's = 194) for study Two. It has been previously stated that if the assumption about supervisors' relative ignorance of the ups and downs of their employees can be confirmed, low correlations can be expected. They are clearly low.

Moreover, this outcome is in accordance with results from comparable studies. Mabe and West (1982) provided an excellent review and meta-analysis of the validity of self-evaluations of ability. Their review of 55 studies including 267 coefficients indicated a mean correlation of .29 between self-reported ability and other ability/performance measurements including tests, grades, supervisory ratings, and, less frequently, performance output.

Elaborating on the 'unrelatedness' of the ratings on the meta-cognition scales, a possible explanation could be the strong inner-directedness and self-reflective loading of this attribute. Meta-cognition is perhaps the most difficult person-bound factor to assess validly. Supervisors, although responsible, are rather too distant most of the time to know their employees more than superficially. Maybe this is why supervisors seem to be somewhat at a loss when facing metacognition. Of course it should be further investigated whether employees are better equipped in this case as self-observers. After all, self-reflection is not something people tend to do much when it comes to rather difficult cognitive skills and their behavioural outcomes.

In study one, paired samples T-tests confirm that, for each scale, the self-ratings are systematically higher than the corresponding supervisor ratings. In other words, employees think somewhat better of themselves than their supervisors do, or at least they give a more positive image of themselves. This result implies that the leniency-effect has been found.

In study two, paired samples T-tests indicate the same outcomes, for three scales. The exception concerns the dimensions of knowledge (the trend being in the expected direction) and social recognition (very identical outcomes for the two sources of raters). 


\section{Conclusions and discussion}

The outcomes of our empirical studies indicate that employees 'think' somewhat better of themselves than supervisors do, or at any rate they give a rosier image. The ratings made by the supervisor are all higher than the corresponding ones made by their employees. This is not caused by the measurement instrument itself, because the scale reliabilities are very high both for the self-ratings and for the supervisor ratings. It has been mentioned before, that the tendency to present themselves positively, the so-called leniency effect, is common in performance ratings. Still, that an item can function differently for different groups of raters suggests the existence of a degree of measurement inequivalence between the rater groups, and this inequivalence may be indicative of systematic bias in ratings between particular groups of raters. This raises important questions about the reliability and objectivity of performance ratings.

It might be that the self-ratings reflect a reliable, but somewhat more differentiated selfimage. The supervisors are more consistent in answering. If they are asked to account for their employee's performance, it seems that they are inclined to give unanimous answers, meaning that the scores for items are more accommodated to each other. That is to say, the ratings made by supervisors are more coloured by the ratings for other items and, also, for other dimensions.

It might be that the supervisor ratings are strongly influenced by a response set, for instance the degree to which they like or dislike the employee in question as a person. It is well known that such liking-disliking factors, or halo effect, can have a strong effect where persons are required to give valid and dependable judgements of other persons, but are not well-informed enough to base their judgement on observations of real-life behaviour of these people or relevant real-life events that they are involved in. Research in the field of organizational justice theory shows that this kind of procedural unfairness has strong effects on the performance and citizenship behaviour of subordinates (Lind, Kulik, Ambrose and Vera Park, 1993; Rutte and Messick, 1995). 
In comparison, ratings by supervisors are based on a much smaller amount of information, leading to the so-called effect of undersampling. The effect of undersampling arises because of the fact that supervisors tend to be more superficially acquainted with their employees, especially in the case of higher level functions. Where they are not able to rely on a large amount of information, they are inclined to fall back upon stereotypes. In other words, the effect of undersampling is thought to give rise to the occurrence of response sets.

An example of a response set that may be due to the effect of undersampling and that can be highly influential is stereotyping, for example on account of age. Age-related stereotyping is an important phenomenon where assessments concerning some quality and performance assessments are made by supervisors. The data from study one and study two indeed confirm that supervisors have a more negative opinion of the functioning of the over-fifties, compared with that of starters and the middle-aged. It seems that stereotyping only starts playing a role of consequence in the highest age group (see Van der Heijden, 1998; 2001 and Van der Heijden, accepted).

Every human being forms stereotypes in order to make his or her world more orderly and predictable. However, many stereotypes are based on cognitive 'errors.' These errors are most likely to occur where people do not have extensive contact with the subject in question and where they do not have any additional information about the individual members of a group. In judging employees whom we do not know very well, we may see them all mainly as members of one and the same group with a common set of - mostly negative - attributes.

Notwithstanding the positive results regarding our operationalization in five dimensions of occupational expertise, the data of the study indicate that the nature of the ratee - self or supervisor - produces very different information about the employee. An explanation for this is the lack of communication between the two parties. The distance between employee and his or her immediate supervisor has previously been referred to. At higher functioning levels especially, employees' work is highly independent and often solitary, even. In order to gain greater insight 
into the potential of one's work force, supervisors should bridge the gap that exists between them and their subordinates. Especially because the fact that the supervisor's opinion is to a great extent influential upon the career of the individual employee.

Perusal of the average correlations between the different groups of raters in both our studies as well as in the studies from other researchers (see for example Alimo-Metcalfe, 1999) suggest that it is not sound from a statistical point of view to aggregate the scores from different sources of raters: for example the employee and the supervisor. In fact, this procedure may be very misleading. We are in danger of conducting statistical analyses without understanding the exact nature of perceptions of occupational competence.

One of the possible lessons of the current study is that we should spend more time in analysing the exact meaning or nature of data on competencies emerging from the 360 degrees feedback methodology. If we do not take the time to do so, we are in danger of conducting 'sophisticated' analyses before understanding the exact nature of perceptions of occupational expertise, i.e. before having established the measurement equivalence.

Specifically, there are two aspects of measurement equivalence: (1) conceptual equivalence, the comparability of constructs; and (2) psychometric equivalence, the comparability of psychometric properties of measurement scales (Cheung, 1999). Conceptual equivalence exists when employees and their supervisors use the same conceptual frame of reference for evaluating performance. That is, raters use the same items to represent dimensions, and assign similar weights to items, appearing from factor form equivalence and factorial invariance. Yet, it is conceivable that employees with less working experience, or less experience in self-evaluation, may use different conceptual frameworks than their supervisors (Mabe and West, 1982; Somers and Birnbaum, 1991).

As regards psychometric equivalence, there have been many studies that examine the psychometric properties of self-rated performance, and response bias such as measurement errors, low variability, and leniency error, to mention some frequently found aspects. When comparing 
self-ratings with supervisor ratings, response bias not only attenuates the power of statistical analyses, but non-equivalent psychometric properties (unequal response sets) also lead to biased results.

It is without doubt that certain items generate ratings that differ between groups of raters, and these differences constitute a substantial part of the richness that is inherent to 360 -degree methodology. Indeed, the between-group rating differences inform the developmental process and drive the use of 360-degree measures. However, the interpretation of between-group rating differences requires that ratings from each item use the same metric, or that measurement equivalence exists across the items. Without measurement equivalence, the comparison of ratings may become problematic (Penny, 2001).

The same would apply to ANY appraisal instrument, whether one uses multiple sources or just a single manager. The fact is that we don't think about this as a problem in case a single manager does the performance appraisal. However, if we consider 5 managers rating the same employee, we would run into the same problem of poor psychometric qualities.

If the appraisal system that we use to make decisions (on mobility, firings, promotions, pay raises, etcetera), can be demonstrated to have low psychometric qualities, it may bring the company to a variety of problems, like law suits and accusations of discrimination on the basis of illegal criteria. Legislation in the United States of America, especially the Federal Sentencing Guidelines, highlights the responsibility of organizations to implement continuous activities to prevent and detect such misconduct (Ferrell, Le Clair and Ferrell, 1998). Absence of these activities will result in higher penalties in case of law suits. Also when it does not result in law suits, decisions that are perceived as unfair will have negative consequences on the motivation, loyalty and extra role behaviour of employees (Ball, Trevino and Sims, 1994; Nijhof, Fisscher and Looise, 2000).

\section{Practical Implications and Recommendations for Human Resource Management Practices}


In order to improve the 360 -feedback methodology, organisations should pay more attention to communication on behaviour of individual employees (Stoker and Van der Heijden, 2001). Direct supervisors and their employees should ask each other regularly for feedback for example based on questionnaire like the one used for the expertise ratings. In order to gain the benefits that the process offers, and minimize the adverse consequences, organizations need to create an atmosphere of trust, openness, and sharing (McNabb and Whitfield, 2001). Feedback is most meaningful when there is a genuine desire on both sides for a meaningful and authentic exchange of perceptions. Walker (1995, p. 141) stresses that for such a mutual understanding it is essential to approach everyone as unique human beings. It also requires an appreciation of the contextual and narrative aspects of certain perceptions because the meaning of these perceptions can only be understood in the concrete situation and its associated history.

Although, initially one has indicated that 360-degree feedback is supposed to be given anonymously, we want to stress that openness is most valuable in the light of the further development of occupational competence. Research has demonstrated that anonymous feedback is more honest and closer to what raters actually feel about the feedback recipients. Appraisers whose identity is known to the feedback recipients give higher ratings than those who are anonymous (London and Smither, 1995; Waldman, Atwater and Antonioni, 1998). Yet, in order to truly make use of knowledge of perception differences and openly share the information, employee and supervisor have an elaborate base of information to talk about the differences in perception (Jones, 2001). Ratings on their own, do not convey sufficient information for people to improve. In order for staff to develop and learn they need to know what they need to change, where (specifically) they have fallen short, and what they need to do. In some cases, a personal coach may be the key to dealing with the inherent discrepancies found in 360-degree ratings.

In situations where a manager's behaviour is evaluated this means that leadership behaviour is something that has to be learned on the 'shop floor', with feedback from employees. 
When leadership skills are developed 'on the job', employees function as co-develop partners and the chances that self-perceptions of leadership competencies do not correspond with the perception of employees will diminish (see also Stoker and Van der Heijden, 2001). The same goes for employees. They should not just learn by means of courses or training programmes, but by working together with their supervisors. Supervisors can be 'sponsors' of several assignments of these courses. In this way, he or she can help facilitate the development of employees.

Another useful way to improve the validity of 360-degrees feedback methodology is lying in the use of perceptions of competencies through the use of a personal development contract. The contract means that employees and their supervisors, in the beginning of a calendar year, agree on which competencies should be developed by employees (this can be done by using one of the questionnaires used in our studies). They both commit themselves to use this contract, and evaluate it at the end of the year.

Also the contract provides activities for both the employee and the supervisor. This means that employees have to develop the competencies that are in the contract, and that supervisors have to support employees by giving them time and resources to develop. In addition supervisors need to gather systematic information on the content and structure of different types of competencies which employees possess. By making this a regular part of the relation between supervisors and employees, supervisors will evaluate their behaviour on a recurrent base and they will recalibrate their own perceptions. In order to make most of the 360-degree methodology, one should include a formal goal-setting component in the system.

Implementing 360-degree feedback for developmental purposes centres on communicating evaluation information to the focal employee. This process is aimed at increasing employees' self-awareness, helping them set goals, focusing on areas of development and, ultimately, altering their behaviour to improve job performance (London and Smither, 1995), and greater dialogue between colleagues (Stoker and Van der Heijden, 2001). 
Another useful way to improve the validity of the 360-degrees feedback methodology can be the application of training and development settings in where both the employees as well as their direct supervisors mutually engage in the development of each others competencies. These programmes should be offered in settings in which the two groups are mixed and in which joined activities can take place. In this way, employees and supervisors learn together and collectively develop their competencies (Ferner, 2000).

It is recommended that all feedback interventions meet the following conditions (DeNisi and Kluger, 2000). Firstly, one should focus on the task and task performance only, not on the person or any part of the person's self-concept. It should be presented in ways that do not threaten the ego of the recipient. It should include information about how to improve performance and clear rules for information sharing have to be formulated. It should include a formal goal-setting plan along with the feedback and it should maximize information relating to performance improvements and minimize information concerning the relative performance of others.

Secondly, one should make sure that the raters are provided with guidance and training, including a description of the major competencies expected of the role (see also Brutus and Derayeh, 2002). Also, raters should be provided with opportunities to detect their own rating biases, if any, before they actually rate an employee.

Thirdly, one should avoid using 360-degree appraisals for decision making. If we also consider the problems that occur when one appraisal is used for both development and for decision making, this advice is more than clear. In case ratings are used for decision making one should tell employees at the earliest possible time in order to prevent them feeling betrayed. Next, help them to interpret and react to the ratings and make sure that the information that is presented is focused on one particular subject and on rater at the same time.

Combining supervisor appraisals and self-assessments may actually serve to decrease defensiveness (Bassett and Meyer, 1968). They may also make apparent any areas of supervisorsubordinate disagreement leading to healthy conflict over the evaluation, and possibly increase 
job performance (Thornton, 1980). Further, there is likely to be an exchange of ideas and the development of 'workable solutions' that are more likely to be accepted by employees due to participation in their development (Gelberd, Lee and Lupton, 1983; Lind, Kulik, Ambrose and Vera Park, 1993)).

In employee development programmes aimed at stimulating one's employability, comparing supervisor ratings and self-assessments can provide useful information on perceived strengths and weaknesses (Hoffman, Nathan and Holden, 1991), and in the identification of training needs, whereby increased motivation is achieved through an individual's recognition of his/her own need for change.

It has even been suggested that employee participation in appraisals could be extended as far as bilateral approaches to personnel selection for certain jobs (George and Smith, 1990; Robertson and Makin, 1986). Hogan (1991) has offered a theoretical rationale for considering the relative efficacy of self versus others' appraisal. The former, it is argued, assesses the person's motives and feelings and the latter assesses reputation. Hogan (1991) argues that reputation (observer ratings) is a better predictor of future job performance than self-assessment and there is some empirical data to support this view (Mount, Barrick and Perkins Strauss, 1994). From the theoretical work of Hogan (1991) it would be expected that those whose self-assessments were closer to the assessments made by the judges (reputation) would be more likely to be selected (see Shrauger and Osberg, 1981). Such self-assessment accuracy may also reflect a more stable underlying individual disposition, that will differentiate amongst candidates.

\section{Recommendations for further research}

It would be very interesting to investigate the degree of overlap between, on the one hand, performance indicators used in companies (for example assessment centres as simulation for 
management selection) and, on the other hand, the results obtained with the measurement instrument that has been developed in this study. This might consequently enable researchers to offer more valuable insights into performance ratings, and to inform organisations with respect to the selection, assessment, and development of managers.

An interesting improvement of the measurements might consist of asking raters to give concrete examples of performances or behaviours of the ratees that could illustrate why they give a particular rating to a particular item. It is expected that a certain amount of sifting of responses occurs. The differentiation between item meanings will probably increase and the scale homogeneities will lessen, but the end results will be that the ratings will be explicitly founded on empirical verifiable observations of behaviour and performance.

If this proves successful, the validity of the instrument will increase and be easier to clarify. The latter refers to the fact that demonstrative examples given by raters could give an insight into the intrinsic content of occupational expertise and expert performance available in an organization. The way in which this can be done is by means of highly structured interviews. They are more dynamic in that possibilities for putting extra questions on a certain topic are within the researcher's reach. 


\section{References}

Alimo-Metcalfe, B. (1999) Do managers, their bosses, direct reports, and colleagues agree as to the nature of effectiveness, and does gender make a difference? Factor analyses of 360 degree/multi-rater feedback. In Pepermans, R., Flion, I., Ardts, J.C.A., and Jansen, P.G.W. (eds), Managerial behaviour. Empirical studies on management development and socialisation. Leuven/Amersfoort: Acco.

Arnold, J. and MacKenzie Daveys, K. (1992) Self-ratings and supervisor ratings of graduate employees' competences' during early career, Journal of Occupational and Organizational Psychology, 65: 235-250.

Ashford, S.J. and Cummings, L.L. (1983) Feedback as an individual resource: Personal strategies of creating information, Organizational Behavior and Human Performance, 32: 370-398.

Bacal, R. (2000) Why ratings based employee appraisals fail? Website: www.work911.com.

Ball, G.A., Trevino, L.K. and Sims, H.P. (1994) Just and unjust punishment: influences on subordinate performance and citizenship, Academy of Management Journal, 37: 2, 299-322.

Bassett, G. and Meyer, H. (1968) Performance appraisal based on self-review, Personnel Psychology, 21: 421-30.

Boerlijst, J.G. (1994) The neglect of growth and development of employees over 40 in organizations: a managerial and training problem. In Snel, J., and Cremer, R. (eds), Work and aging (pp. 251-271). London: Taylor and Francis Ltd.

Boerlijst, J.G. and Van der Heijden, B.I.J.M. (1996). Human Resources Management in Distress: Pitfalls for Gifted Workers in Organizations. In Munandar, U. and Semiawan, C. (eds) Optimizing Excellence in Human Resource Development (Proceedings of the Fourth Asia Pacific Conference on Giftedness, Jakarta, 4-8 August 1996), pp. 473-480. Jakarta: University of Indonesia Press (ISBN 979-459-169-X). 
Boerlijst, J.G., Van der Heijden, B.I.J.M. and Van Assen, A. (1993). Veertig-plussers in de onderneming [Over-forties in the organization]. Assen: Van Gorcum/Stichting Management Studies.

Borman, W.C. (1998) 360 degree ratings: An analysis of assumptions and a research agenda for evaluating their validity, Human Resource Management Review, 7: 299-315.

Brutus, S. and Derayeh, M. (2002) Multisource assessment programs in organizations: An insider's perspective, Human Resource Development Quarterly, 13, 2: 187-202.

Caligiuri, P. and Lazarova, M. (2002) A model for the influence of social interaction and social support on female expatriates'cross-cultural adjustment, International Journal of Human Resource Management, 13, 5: 762-772.

Campbell, D.J. and Lee, C. (1988) Self-appraisal in performance evaluation: Development versus evaluation, Academy of Management Review, 13, 2: 302-314.

Cascio, W.F. (1991) Applied psychology in personnel management. London: Prentice-Hall International.

Cleveland, J.N., Murphy, K.R. and Williams, R.E. (1989) Multiple uses of performance appraisal: Prevalence and correlates, Journal of Applied Psychology, 74: 130-35.

Cheung, G.W. (1999) Multifaceted conceptions of self-other ratings disagreement, Personnel Psychology, 52: 1-36.

Cooper, W. (1981) Ubiquitous halo, Psychological Bulletin, 90: 218-44.

Cronbach, L.J. (1990) Essentials of psychological testing. New York: Harper Collins Publishers.

DeNisi, A.S. and Kluger, A.N. (2000) Feedback effectiveness: Can 360-degree appraisals be improved? The Academy of Management Executive, 14, 1: 129-139.

Dunnette, M.D. (1993) My hammer or your hammer? Human Resource Management, 32: 373-84.

Farh, J. and Dobbins, G. (1989) Effects of comparative performance information on the accuracy of self-ratings and agreement between self and supervisor ratings, Journal of Applied Psychology, 74: 606-10. 
Ferner, A. (2000) The Underpinnings of 'Bureaucratic' Control Systems: HRM in European Multinationals, Journal of Management Studies, 37, 4: 521-40

Ferrell, O.C., Le Clair, D.T. and Ferrell, L. (1998) The federal Sentencing Guidelines for organizations; A framework for ethical compliance, Journal of Business Ethics, 3: 353-63

Fox, S. and Dinur, Y. (1988) Validity of self-assessments: a field evaluation, Personnel Psychology, 41: 581-592.

Gelberd, L., Lee, C. and Lupton, D. (1983) Self-appraisals - the next stage in performance evaluation, Supervisory Management, May, 9-14.

George, D. and Smith, M. (1990) An empirical comparison of self-assessment and organizational assessment in personnel selection, Public Personnel Management, 19: 175-90.

Greenberg, J. (1986) The Distributive Justice of Organizational Performance Evaluations. In Bierhoff, H.W., Lo Cohen, R. and Greenberg, J. (eds) Justice in social relations. New York: Plenum Press, 337-51.

Golden, B.R. (1992) The past is the past? - Or is it? The use of retrospective accounts as indicators of past strategy, Academy of Management Journal, 35: 848-60.

Harris, M.M. and Schaubroeck, J. (1988) A meta-analysis of self-supervisor, self-peer, and peersupervisor ratings, Personnel Psychology, 41: 43-62.

Hoffman, C.C., Nathan, B.R. and Holden, L.M. (1991) A comparison of validation criteria: objective versus subjective performance measures and self- versus supervisor ratings, Personnel Psychology, 44: 601-19.

Hogan, J.C. (1991) Personality and personality assessment. In Dunette, M.D. and Hough, L.M. (eds) Handbook of Industrial and Organizational Psychology (pp. 973-1019). Palo Alto, CA.: Consulting Psychologist Press.

Holzbach, R.L. (1978) Rater bias in performance ratings: Superior, self-, and peer ratings, Journal of Applied Psychology, 63, 5: 579-588. 
Huber, G.P. and Power, D.J. (1985) Retrospective reports of strategic level managers: Guidelines for increasing their accuracy, Strategic Management Journal, 6: 171-80.

Jones, E.E. and Nisbett, R.E. (1971) The actor and the observer: Divergent perceptions in the causes of behaviour. New York: General Learning Press.

Jones, M.L. (2001) Sustainable organizational capacity building: is organizational learning a key? International Journal of Human Resource Management, 12, 1: 91-98.

Judge, T.A. and Ferris, G.R. (1993) Social context of performance evaluation decisions, Academy of Management Journal, 36: 80-105.

Kozlowski, S.W.J. and Kirsch, M.P. (1987) The systematic distortion hypothesis, halo, and accuracy: An individual-level analysis, Journal of Applied Psychology, 72: 252-61.

Levine, E.L. (1980) Introductory remarks for the symposium 'Organizational applications of selfappraisal and self-assessment: Another look", Personnel psychology, 33: 259-62.

Lind, E.A., Kulik, C.T., Ambrose, M. and Vera Park, M.V. (1993) Individual and Corporate dispute resolution; Using Procedural Fairness as a Decision Heuristic, Administrative Science Quarterly, 38: 223-51.

London, M. and Smither, J.W. (1995) Can multisource feedback change perceptions of goal accomplishment, self-evaluations, and performance-related outcomes? Theory-based applications and direction for research, Personnel Psychology, 48: 803-39.

Mabe, P. and West, S. (1982) Validity of self-evaluation of ability: a review and meta-analysis, Journal of Applied Psychology, 67: 280-96.

McNabb, R. and Whitfield, K. (2001) Job evaluation and High Performance Work Practices: Compatible of Conflictual? Journal of Management Studies, 38, 2: 293-312

Miller, M.J. (1996) Rater individual differences and accuracy in performance appraisal. A thesis submitted to the Office of Graduate Studies of Texas A\&M University.

Monson, T.C. and Snyder, M. (1977) Actors, observers, and the attribution process, Journal of Experimental Social Psychology, 13: 89-111. 
Mount, M., Barrick, M. and Perkins Strauss, J. (1994) Validity of observer ratings of the big five personality factors, Journal of Applied Psychology, 79: 272-280.

Nijhof, A.H.J., Fisscher. O.A.M. and Looise, J.C. (2000) Coercion, Guidance and Mercifulness: The different approaches of Ethics Programs on Decision-Making, Journal of Business Ethics, 27: 33-42.

Nisbett, R.E. and Wilson, T.D. (1977) Telling more than we can know: Verbal reports on mental processes, Psychological Review, 84: 231-59.

Penny, J. (2001) Differential item functioning in an international 360-degree assessment: Evidence of gender stereotype, environmental complexity, and organizational contingency, European Journal of Work and Organizational Psychology, 10, 3: 245-71.

Podsakoff, P. and Organ, D. (1986) Self-reports in organizational research: Problems and prospects, Journal of Management, 12: 531-44.

Rutte, G. and Messick, D.M. (1995) An integrated model of perceived unfairness in Organizations, Social Justice Research, 8, 3: 239-61

Robertson, I. and Makin, P. (1986) Management selection in Britain: a survey and critique, Journal of Occupational Psychology, 59: 45-57.

Shore, L.M. and Thornton, G.C. III (1986) Effects of gender on self- and supervisory ratings, Academy of Management Journal, 29: 115-29.

Shrauger, S.J. and Osberg, T.M. (1981) The relative accuracy of self-prediction and judgments by others in psychological assessment, Psychological Bulletin, 90: 322-51.

Smith, B.N., Hornsby, J.S. and Shirmeyer, R. (1996, Summer) Current trends in performance appraisal: An examination of managerial practice, SAM Advanced Management Journal: 1015.

Somers, M.J. and Birnbaum, D. (1991) Assessing self-appraisal of job performance as an evaluation device: Are the poor results a function of method or methodology? Human Relations, 44: 1069-91. 
Stewart, J. (1998) Intervention and assessment: the ethics of HRD, Human Resource

Development International, 1, 1: 9-12.

Stoker, J.I. and Van der Heijden, B.I.J.M. (2001) Competence development and appraisal in organizations, Journal of Career Development, 28, 2: 97-113.

Thornton, G. (1980) Psychometric properties of self-appraisal of job performance, Personnel Psychology, 33: 262-71.

Tornow, W.W. (1993) Perceptions or reality: Is multi-perspective measurement a means or an end? Human Resource Management, 32: 221-30.

Tsui, A.S. and Ohlott, P. (1988) Multiple assessment of managerial effectiveness: interrater agreement and consensus in effectiveness models, Personnel Psychology, 41: 779-803.

Van der Heijden, B.I.J.M. (1998) The measurement and development of professional expertise throughout the career. A retrospective study among higher level Dutch professionals. PhDthesis. University of Twente, Enschede, the Netherlands. Enschede: PrintPartners Ipskamp.

Van der Heijden, B.I.J.M. (2000) The development and psychometric evaluation of a multidimensional measurement instrument of professional expertise, High Ability Studies The Journal of the European Council for high ability, 11, 1: 9-39.

Van der Heijden, B.I.J.M. (2001) Age and assessments of professional expertise. The relationship between higher level employees' age and self-assessments or supervisor ratings of professional expertise, International Journal of Selection and Assessment, Vol. 9, 4: 309324.

Van der Heijden, B.I.J.M. (accepted) Age and assessments of professional expertise in small and medium-sized enterprises: Differences between self-ratings and supervisor ratings. International Journal of Human Resource Development and Management.

Van der Heijden, B.I.J.M. and Verhelst, N.D. (2002) The psychometric evaluation of a multidimensional measurement instrument of professional expertise. Results from a study in small 
and medium-sized enterprises in the Netherlands, European Journal of Psychological Assessment, 18, 2: 165-178.

Waldman, D.A. and Atwater, L.E. (1998) The power of 360-degree feedback: How to leverage performance evaluations for top productivity. Houston: Gulf.

Waldman, D.A., Atwater, L.E., and Antonioni, D. (1998) Has 360-degree feedback gone amok? Academy of Management Executive, 12: 86-94.

Walker, M.U. (1995) Moral Understandings, Alternative 'epistemology' for a feminist Ethics. In Held, V., (ed) Justice and Care. (pp. 139-152). Colorado: Westview Press of HarperCollins Publishers.

Wolfe, J. and Jackson, C. (1987) Creating models of strategic decision making process via participant recall: A free simulation examination, Journal of Management, 13: 123-34.

Yammarino, F.J. and Atwater, L.E. (1997) Do managers see themselves as others see them? Implications of self-other rating agreement for human resources management, Organizational Dynamics: $35-44$. 